\title{
MCDA PARA AVALIAR O DESEMPENHO DE UM CURSO DE PÓS-GRADUAÇÃO
}

\author{
MCDA TO EVALUATE THE PERFORMANCE OF A COURSE POSTGRADUATE
}

\author{
Gisele Mazon \\ Universidade do Sul de Santa Catarina
}

\section{Fernando Ribeiro Serra}

Universidade do Sul de Santa Catarina

\section{Marcus Vinícius Andrade de Lima}

Universidade do Sul de Santa Catarina

Thiago Coelho Soares

Universidade do Sul de Santa Catarina

\section{RESUMO}

Este artigo objetiva apresentar a estrutura de uma metodologia de avaliação de desempenho para um curso de pós-graduação Lato Sensu na área de gestão pela metodologia Multicritério em Apoio a Decisão Construtivista (MCDA). Como as percepções e valores variam para cada organização, neste estudo será apresentada a estrutura para uma universidade comunitária. Esta pesquisa de caráter qualitativo, consistiu-se em um estudo de caso, com investigação em duas etapas: bibliográfica, e outra documental e a aplicação de questionário. Com a aplicação da metodologia MCDA, a partir das percepções e valores identificados, pôde-se verificar o desempenho do curso de pós graduação em diversos níveis: mercado, marca, docente, infraestrutura e operacionalização. Verificou-se que o curso tem como nível crítico a parceria com o mercado. Já a titulação do professores e a localização do curso foram consideradas nível de excelência.

Palavras-chave: Avaliação de desempenho. MCDA. Lato sensu.

\begin{abstract}
This article presents the structure of a methodology for performance evaluation for a course of postgraduate Sensu Lato in the management methodology for Multicriteria Decision Support Constructivist (MCDA). As the perceptions and values vary for each organization, this study will be presented the framework for a community college. This qualitative research consisted in a case study with research in two stages: literature and other documentary and a questionnaire. With the application of MCDA methodology, based on the perceptions and values identified, we could check the performance of graduate course at various levels, market, brand, faculty, infrastructure and operations. It was found that the course is the critical level associated with the market. Already the titration of the teachers and the location of the course were considered level of excellence.
\end{abstract}

Keywords: Performance evaluation. MCDA. Lato sensu. 


\section{INTRODUÇÃo}

Conforme Teixeira (2005) a missão de uma universidade é preparar o individuo para a vida profissional e que, para isso, possuam como base a técnica intelectual científica, seguida pela importante função de expandir o conhecimento, estimulando assim a criatividade do acadêmico pela busca do saber, transmitindo assim acultura comum da nação. Tal instituição é capaz de ofertar a sua comunidade acadêmica cursos de graduação, lato sensu e stricto sensu, ou seja, uma educação "ao longo da vida". Neste sentido a educação permanente deverá, inevitavelmente, ser compreendida de modo muito mais abrangente e qualificada da forma como é entendida hoje.

No Brasil destaca-se a discussão pela utilização de critérios de "qualidade" na oferta do lato sensu. De um lado, questionam-se estrutura, falta de articulação com o stricto sensu e, por conseqüência, a ausência da tradição acadêmica nas políticas de criação e implantação de cursos. Discute-se também a falta de acompanhamento, avaliação e controle por parte das instâncias reguladoras quanto às diretrizes nacionais. De outro, questiona-se a resistência quanto a uma visão menos restritiva dos marcos regulatório e sistemas de avaliação, justamente para garantir o dinamismo característico deste nível de aprendizagem. Como característica principal, reconhece-se que o lato sensu desenvolveu-se sem identidade conceitual, sem vínculo com o sistema nacional de pós-graduação e fora das políticas que norteiam a graduação. (BURGER et all, 2008)

O objetivo do MCDA, fundamentados em uma visão denominada de construtivista, é de gerar conhecimento para o processo decisório. Os modelos construídos por meio do processo de apoio à decisão permitem identificar oportunidades de aperfeiçoamento, assim como, base para entender o impacto que as ações exercem sobre os seus valores. Dentro da visão da metodologia MCDA, deve-se perceber que a função é melhorar o desempenho do contexto e que as possíveis soluções são apenas meios para tal, mas o foco é no aperfeiçoamento do desempenho, representado por seus objetivos (ENSSLIN ET AL 2001).

Neste sentido, para que se crie uma identidade institucional de qualidade na oferta de cursos, e se torne competitiva no mercado de pós graduação lato sensu, optou-se por utilizar a metodologia Multicritério em Apoio a Decisão Construtivista (MCDA), por se tratar de uma metodologia que fornece uma abordagem estruturada do contexto a partir das percepções e valores envolvidos no processo decisorial.

Neste contexto, este artigo foca seu estudo em um curso lato sensu na área de gestão da Universidade do Sul de Santa Catarina, Unisul. A opção em se aplicar o presente estudo na Unisul se deu pela mesma estar a quase meio século no mercado e, no atual ano, estar readequando a oferta de novos cursos de lato sensu.

Desse modo, o objetivo do deste artigo é apresentar uma estrutura de avaliação de desempenho para o curso de pós-graduação lato sensu na área de gestão, utilizando a metodologia MCDA-C. O presente estudo está estruturado da seguinte forma: Referencial Teórico - com uma breve abordagem teórica sobre a pós-graduação lato sensu e MCDA; Metodologia utilizada; Apresentação dos Resultados - onde será descrito e apresentado o modelo proposto para o estudo; Considerações Finais; e, Referências Bibliográficas.

\section{REFERENCIAL TEÓRICO}

Neste item apresentaremos os temas-eixos que norteiam nossa pesquisa - a pós-graduação lato sensu das Instituições de Ensino Superior e a Metodologia Multicritério de Apoio a Decisão Construtivista (MCDA-C).

PÓS-GRADUAÇÃO LATO SENSU

Conforme Colossi, Conssentino e Queiroz (2001), entende-se por educação superior uma instituição 
social que tem como finalidade a formação intelectual e científica da sociedade onde esta se encontra. A instituição social caracteriza-se por apresentar estabilidade e durabilidade de sua missão e repousa sua estrutura em normas e valores do grupo ou sociedade em que se insere.

Quanto a formação dos cursos de pós-graduação lato sensu, estes foram reconhecido depois de 1965, com o parecer do professor Newton Sucupira (MEC/ CFE/CES 997/1965). O lato sensu protagonizou outras funcionalidades para a pós-graduação no contexto educacional brasileiro. Até então, os cursos de especialização tinham como fundamento a formação de professores e como pressupostos, concepções acadêmicas de estruturação de oferta. Serviam, portanto, como base para a composição de um corpo docente capaz de sustentar os investimentos em pesquisa e programas de stricto sensu, considerados necessários para o desenvolvimento nacional ao longo desse processo. Entendidos como mais abrangentes na proposta, os cursos lato sensu foram "institucionalizados" na década de 60 por uma política governamental federal que buscava a expansão do sistema de ensino superior através de uma divisão clara entre IES para elites (universidades públicas e gratuitas) e IES para as massas (instituições que compunham uma rede privada e autônoma). (BURGER et all 2008)

Formalmente, foi com a Lei de Diretrizes e Bases para a Educação (Lei no 9.394 de 20 de dezembro de 1996), que o lato sensu consolidou-se no sistema de educação brasileiro. Todavia, em todo o seu processo de desenvolvimento, nunca foi inserido nos órgãos responsáveis pela avaliação educacional no Brasil. Em 2004, o MEC instituiu a Comissão Especial de Acompanhamento e Verificação, ligada à Secretaria de Ensino Superior (SESu), para acompanhar e fiscalizar os cursos lato sensu (portaria 1180 de 6 de maio de 2004). Há um entendimento de que tais cursos estariam mais ligados à graduação que ao stricto sensu. A própria estrutura criada pelo MEC evidencia isso, na medida em que retira da CAPES (instância que normatiza os cursos de stricto sensu) essa responsabilidade. Tal proposição garante às IES que têm autonomia didático-científica e administrativa, prerrogativa constitucional dada às instituições universitárias, a possibilidade de ofertar cursos lato sensu sem a necessidade de reconhecimento.

Por esta razão, conforme dados do Instituto Nacional de Estudos e Pesquisas Educacionais Anísio Teixeira -INEP- (2007), no Brasil existem 8.866 cursos de pós-graduação lato sensu. Na região Sudeste está concentrada o maior quantidade de cursos, são 4.955, o que corresponde a 55,9\% do total. As regiões Nordeste e Centro-Oeste somam mais de 1.200 cursos, número superior aos 951 que se encontram na Região Sul. Esta quantidade de cursos de pós-graduação lato sensu no Brasil deriva, principalmente, da expansão e oferta por meio das Instituições de Ensino Superior (IES) privadas. Estas instituições ofertam 7.939 cursos, ou seja, 89,5\% do total. Entre os públicos, nas instituições municipais estão 412 (4,6\%), nas estaduais, 269 (3\%), e nas federais, 246 (2,8\%). Em relação à organização acadêmica, a grande maioria dos cursos de especialização existentes no país está em faculdades: 7.567 (85,3\%). Já as universidades concentram $920(10,4 \%)$ do total de cursos e os centros universitários $379(4,3 \%)$.

\section{METODOLOGIA MULTICRITÉRIO DE APOIO A DECISÃO CONSTRUTIVISTA (MCDA-C)}

O MCDA é uma ferramenta que auxilia o gestor a gerir seus problemas de acordo com suas percepções de valor, levando em consideração aspectos qualitativos e quantitativos. "Um problema pertence a uma pessoa, isto é, ele é uma construção pessoal que o indivíduo faz sobre os eventos associados ao contexto decisório". (ENSSLIN ET AL, 2001, p. 75)

A metodologia MCDA-C construtivista permite uma evolução específica do conhecimento no processo de apoio à decisão, ou ainda, considera um desenvolvimento progressivo do entendimento do processo decisório dentro de algumas particularidades. Tratar-se-á nesta etapa de discutir a estruturação do problema, considerada como sendo a fase mais importante relacionada à atividade de estudo de problemas complexos nas organizações (CAMPOS, 2005).

A metodologia Multicritétio de Apoio à Decisão Construtivista (MCDA-C) adotada neste trabalho segue 
a corrente de pensamento da Escola Européia (Multicriteria Decision Aid), segundo a vertente construtivista. Adotar a perspectiva da MCDA-C significa acatar os seguintes entendimentos: (a) um problema é configurado como tal se for assim percebido por alguém (tem um 'dono'); resultante de uma situação percebida como necessitando de intervenção; suficientemente relevante; passível de solução (LANDRY, 1995, p.313); (b) o entendimento do problema pressupõe a noção de produção de conhecimento por meio da descoberta de como o sujeito valora o contexto onde o objeto se encontra; assim, levam-se em conta os sistemas de valores, convicções e objetivos dos envolvidos, o momento atual e o grau de entendimento do decisor sobre todo o contexto; e (c) o reconhecimento do fato de que "não existe apenas um conjunto de ferramentas adequado para esclarecer uma decisão nem exis te uma única melhor maneira de fazer uso delas" (ROY, 1993, p.194).

\section{Operacionalização dos Fundamentos da Metodologia MCDA-C}

Para a operacionalização dos fundamentos da metodologia MCDA-C ocorre por meio de três fases básicas, diferenciadas, mas correlacionadas: a estruturação do contexto decisório; a construção de um modelo de avaliação de alternativas/ações; e, a formulação de recomendações para os cursos de ações mais satisfatórios

\section{Fase de estruturação}

O processo de estruturação é de suma importância para se ter um entendimento comum sobre o problema, orientar o processo de criação das ações e, por fim, servir de base para o processo de avaliação das mesmas. É nesta fase que o facilitador deve investir a maior parte do tempo disponível. 0 facilitador é quem aplica as ferramentas e irão: apoiar o raciocínio; gerar o conhecimento; e, comunicar sobre a realidade. (ENSSLIN et al, 2001).

É, também, nesta fase do processo decisório que os valores dos decisores serão levados em conta a respeito da situação do problema. Nesta etapa, são de extrema relevância as considerações de Keeney (1992) a respeito do "pensamento focado no valor", ou seja, focar nos valores dos decisores para que eventuais objetivos existentes, que estejam ocultos, sejam considerados e, desta forma, permitam obter mais consistência nas decisões.

Ensslin (2003), cita que "o processo para construir o modelo deve estar fundamentado no fato de que o decisor tem pleno arbítrio sobre o mesmo e, desta forma, o modelo e os conhecimentos desenvolvidos tem como propósito servir como elementos de reflexão para seu entendimento pelo decisor e demais atore". Por "atores", entende-se como sendo todos os indivíduos envolvidos no processo decisório.

Como primeira etapa a ser considerada temos a definição, junto ao decisor, de um "rótulo para o problema". A função principal do rótulo é de delimitar o contexto decisório nesta etapa do processo, não sendo, portanto, definitivo. Ensslin et al (2001) destaca que o facilitador deve definir o rótulo de acordo com a forma com que os decisores consideram a mais adequada.

A segunda etapa na construção dos mapas de relações meios-fins é a definição dos Elementos Primários de Avaliação (EPA's). Keeney (1992) menciona que estes elementos constituem-se de objetivos, metas e valores dos decisores e também de ações, opções e alternativas.

A partir dos EPA'S, pode-se definir os Pontos de Vista Fundamentais (PVF's). Segundo Ensslin et al (2001), definida a Família de Pontos de Vista Fundamentais (PVF’s), dá-se início a construção do modelo multicritério para a avaliação das ações potenciais. Sendo, portanto, necessário a construção de um critério que permita mensurar a desempenho de cada ação potencial. Ressalta-se aqui que: "o objetivo de MCDA Construtivista é gerar conhecimento, a avaliação a ser realizada será apenas um meio para que o decisor tenha domínio da situação do problema" (ENSSLIN, 2003).

A construção dos descritores consiste na identificação dos níveis BOM e NEUTRO. Ensslin et al (2001) 
destaca que, além de importantes no processo de verificação da independência preferencial e para a determinação das taxas de substituição, os níveis definidos são "referenciais de desempenho", podendo identificar ações com desempenho competitivo, ou seja, entre os níveis bom e neutro, bem como, ações com desempenho comprometedor ou de excelência - abaixo do nível NEUTRO e acima do nível BOM, respectivamente.

\section{Fase de avaliação}

Após a fase de estruturação do modelo multicritério, por meio da construção dos Pontos de Vista Fundamentais e seus respectivos descritores, decorre-se então para a fase de avaliação. Nesta fase são construídas as funções de valor e determinadas as taxas de compensação do modelo.

Destacou-se método do julgamento semântico, mais especificamente ao método MACBETH (Measuring Attractiveness by a Categorical Based Evaluation Technique) de Bana e Costa e Vansnick (1995). O diferencial no método citado justifica-se basicamente pela simplicidade percebida pelo próprio decisor, pois o mesmo utiliza-se de julgamentos semânticos de "diferenças de atratividade" para determinar a função de valor correspondente. As categorias semânticas de diferença de atratividade utilizadas pelo MACBETH são: nenhuma; muito fraca; fraca; moderada; forte; muito forte; e, extrema. Com base na comparação entre a diferença de atratividade dos impactos considerados para cada ação, é estabelecida a matriz semântica que corresponde ao julgamento do decisor referente às diferenças de atratividade.

As taxas de compensação, também chamadas de taxas de substituição, "estas expressam a perda ou ganho de desempenho que uma ação potencial deve sofrer em um critério para compensar o ganho ou perda de desempenho em outro" (ENSSLIN et al, 2001). Dentre os métodos para determinação de taxas de compensação, destaca-se o MACBETH, que adota lógica similar àquela utilizada para determinação de função de valor, ou seja, a do julgamento semântico.

\section{Fase de recomendações}

Para Ensslin (2002), este é o momento em que serão sugeridos e discutidos futuros cursos de ações para a situação decisional. Keeney (1992) destaca algumas possibilidades para o uso de um modelo multicritério construído, dentre elas: 0 modelo pode ser utilizado para avaliar ações descrevendo as suas conseqüências; 0 modelo pode ser utilizado para criar ações; 0 modelo pode auxiliar na canalização das discussões entre os decisores para aquilo que é mais importante; 0 modelo pode ser utilizado para a defesa e justificativa de ações.

Nesta fase, existem duas atividades importantes, a geração e avaliação de ações e a análise de sensibilidade.

Já a análise de sensibilidade, de acordo com Goodwin et al (1991), normalmente é utilizada para se efetuar o exame do comportamento das performances globais em frente a sensíveis variações nos valores dos parâmetros aplicados no modelo de apoio à decisão. Neste contexto, é recomendado que a análise de sensibilidade seja aplicada no modelo.

\section{MÉTODO DE PESQUISA}

Esta pesquisa teve caráter qualitativo. A pesquisa qualitativa, de acordo com Triviños (1994), permite analisar os aspectos implícitos ao desenvolvimento das práticas organizacionais e a interação entre seus integrantes. É a técnica mais apropriada para compreender o fenômeno no contexto onde está inserida e do qual é parte, pois possibilita analisá-lo numa perspectiva integrada. Quanto aos fins pode ser considerada descritiva. É descritiva, pois descreve as informações obtidas por meio da pesquisa documental e entrevistas. Para Churchill (1987), pesquisa descritiva objetiva conhecer e interpretar a realidade sem nela interferir para modificá-la. A pesquisa descritiva expõe as características de determinada população ou de determinado fenômeno, mas não tem o compromisso de explicar os 
fenômenos que descreve, embora sirva de base para tal explicação.

Quanto a estratégia de pesquisa se utilizou o estudo de caso. Por se ter estudado um único fenômeno, este estudo focou-se no entendimento da dinâmica presente dentro de um único ambiente, (YIN, 2001) em um curso lato sensu na área de gestão da Unisul.

Quanto aos meios de investigação, este trabalho foi dividido em duas etapas, uma inicial que foi a pesquisa bibliográfica, e outra final que foi a pesquisa documental e a aplicação de questionários.

Conforme Vergara (1998), a pesquisa bibliográfica é um estudo sistematizado desenvolvido com base em material publicado em livros, revistas, meios eletrônicos e jornais. Fornece instrumental analítico para a pesquisa.

Yin (2001) afirma que a documentação é uma fonte estável de coleta de dados, tendo em vista que pode ser revista inúmeras vezes, além de ser exata por conter nomes, referências e detalhes como também possui uma ampla cobertura, pois abrange longos períodos de tempo e espaço. Porém, o autor ressalta que o acesso aos documentos pode ser dificultoso e caso não seja realizado uma pesquisa completa pode tendênciar a pesquisa. Foi analisado um documento com as perspectivas para a pósgraduação lato sensu da Unisul.

Durante este trabalho, retirou-se elementos que fundamentassem e compusessem este artigo, como por exemplo, da análise SWOT (pontos fortes e pontos fracos, oportunidades e ameaças), chegamos aos elementos primários de avaliação. De posse dos elementos primários, agrupados em cinco áreas de interesse, Mercado, Marca, Docente, Infra-Estrutura, Operacionalização se propôs uma árvore de pontos de vista, conforme o modelo do autor Keeney (1992). E, para nos auxiliar no cálculo das funções de valor contamos com o auxilio do software MacBeth.

\section{APRESENTAÇÃO DOS RESULDATOS}

Demonstra-se a operacionalização da metodologia MCDA-C no contexto do gerenciamento do curso de pós-graduação lato sensu na área de gestão da Unisul. Primeiramente será apresentada a fase de estruturação, na seqüência a de avaliação e por fim a fase de recomendações.

\section{FASE DE ESTRUTURAÇÃO}

Com o intuito de estruturar o modelo fez-se a caracterização do contexto decisório e a identificação dos atores.

Descrição do Contexto: o resultado das grandes organizações não depende apenas dos ativos tangíveis, mas também dos intangíveis, o que podemos chamar de capital intelectual. Assim as organizações cada vez mais precisam medir e evidenciar estes resultados.

Caracterização do Contexto Decisório: A insatisfação do gestor do curso de pós-graduação lato sensu da Unisul, quanto ao desempenho do curso.

Identificação dos Atores: como decisor foi definido o gestor do curso de pós-graduação lato sensu da Unisul.

A partir desta descrição passamos para a segunda etapa. Inicialmente, por meio de análise SWOT identificou-se 53 (cinqüenta e três) Elementos Primários de Avaliação (EPAs) devidamente agrupados em 5 (cinco) áreas de interesse: Mercado, Marca, Docente, Infra-Estrutura e Operacionalização. A partir desses EPA's e seus agrupamentos foi possível propor uma Árvore de Pontos de Vistas (KEENEY, 1992), conforme a Figura 1. 
Figura 1: Árvore de Pontos de Vistas

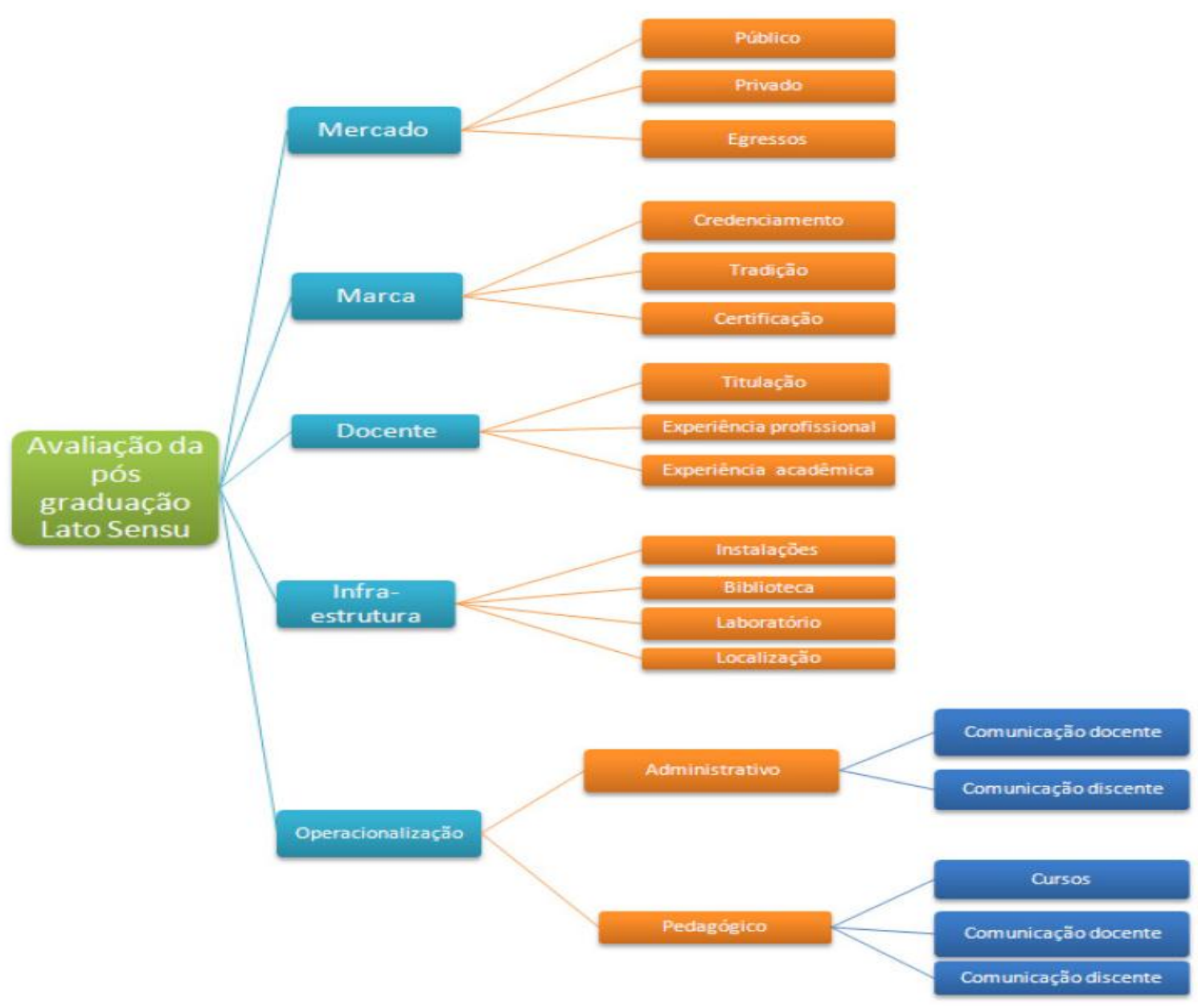

Fonte: Elaborado pelos autores a partir do modelo de Keeney 1992

Possuindo a Árvore de Pontos de Vista elaboraram-se os descritores. Nos descritores são identificados os níveis de impacto de cada um dos pontos de vista, permitindo assim a mensuração e avaliação do modelo. Assim, para cada descritor foram definidos níveis âncora de referência, conforme exposto na Quadro 1.

\section{Quadro 1: Exemplo de níveis de referência para MARCA.}

\begin{tabular}{|l|l|l|}
\hline \hline \multicolumn{2}{|c|}{ Descritor: Credenciamento } \\
\hline Níveis & Ancora & Descrição \\
\hline N2 & BOM & Possui credenciamento com assosiaçōes da área. \\
\hline N1 & NEUTRO & Não possui credenciamento com assossiaçōes da área. \\
\hline \hline
\end{tabular}

\begin{tabular}{|l|l|l|}
\hline \hline \multicolumn{2}{|c|}{ Descritor: Certificação } \\
\hline Níveis & Ancora & Descrição \\
\hline N2 & BOM & Possui certificação do conselho da área. \\
\hline N1 & NEUTRO & Não possui certificação do conselho da área. \\
\hline \hline
\end{tabular}

\begin{tabular}{|l|l|l|}
\hline \multicolumn{2}{|c|}{$\mid$} \\
\hline Niveis & Ancora & Descriçāo \\
\hline N4 & & Atuante no mercado acima de 50 anos \\
\hline N3 & BOM & Atuante no mercado de 30 a 49 anos \\
\hline N2 & & Atuante no mercado de 10 a 29 anos \\
\hline N1 & NEUTRO & Atuante no mercado de 0 a 9 \\
\hline
\end{tabular}

Fonte: Elaborado pelos autores 
Estes níveis definem os limites superiores (considerado Bom) e inferiores (considerado Neutro), onde os resultados são identificados como níveis de mercado. Para os níveis acima de "Bom" o resultado é considerado benchmarking, é o nível de excelência. Para os níveis abaixo de "Neutro" o resultado é considerado comprometedor, pois está abaixo do esperado pelo gestor.

\section{FASE DE AVALIAÇÃO}

Posteriormente a conclusão do estudo dos descritores, determina-se o grau de atratividade entre os níveis de descritores, através de uma função de valor (ver Quadro 2 - colunas 4 a 7). As funções de valor foram elaboradas com o auxilio do software Macbeth. A partir destes dados podem-se fazer inferências quanto ao desempenho de cada um destes níveis.

A etapa final da construção consiste em identificar as taxas de compensação de cada um dos PV's do modelo, ver quadro 2 - coluna 8. Assim, o modelo de avaliação de desempenho do curso de pós-graduação lato sensu da Unisul está apto a ser utilizado.

\section{Quadro 2: Níveis dos descritores e taxas de compensação}

\begin{tabular}{|c|c|c|c|c|c|c|c|}
\hline $\begin{array}{l}\text { Ponto de Vista } \\
\text { Fundamental (PVF) }\end{array}$ & PVE & Descritor & N1 & N2 & N3 & N4 & $\begin{array}{c}\text { Taxa de } \\
\text { compensação }\end{array}$ \\
\hline \multirow{3}{*}{$\begin{array}{l}\text { PVF1 - } \\
\text { Mercado }\end{array}$} & PVE1 & Público & -125 & 0 & 100 & 175 & $16,7 \%$ \\
\hline & PVE2 & Privado & -125 & 0 & 100 & 175 & $33,3 \%$ \\
\hline & PVE3 & Egresso & -125 & 0 & 100 & 175 & $50 \%$ \\
\hline \multirow{3}{*}{$\begin{array}{l}\text { PVF2 - } \\
\text { Marca }\end{array}$} & PVE4 & Credenciamento & 0 & 100 & & & $10 \%$ \\
\hline & PVE5 & Certificação & 0 & 100 & & & $30 \%$ \\
\hline & PVE6 & Tradição & -80 & 0 & 100 & 160 & $60 \%$ \\
\hline \multirow{3}{*}{$\begin{array}{l}\text { PVF3 - } \\
\text { Docente }\end{array}$} & PVE7 & Titulação & -125 & 0 & 100 & 175 & $62 \%$ \\
\hline & PVE8 & Exp. Profissional & -80 & 0 & 100 & 160 & $31 \%$ \\
\hline & PVE9 & Exp. Acadêmica & -80 & 0 & 100 & 160 & $7 \%$ \\
\hline \multirow{4}{*}{$\begin{array}{l}\text { PVF4 - } \\
\text { Infra-estrutura }\end{array}$} & PVE10 & Instalações & -100 & 0 & 100 & 180 & $46 \%$ \\
\hline & \begin{tabular}{|l|} 
PVE11 \\
\end{tabular} & Biblioteca & -100 & of & 100 & 180 & $32 \%$ \\
\hline & PVE12 & Laboratório & -100 & 0 & 100 & 180 & $18 \%$ \\
\hline & \begin{tabular}{|l|l} 
PVE13 \\
\end{tabular} & Localização & -100 & 0 & 100 & 200 & $4 \%$ \\
\hline \multirow{2}{*}{$\begin{array}{l}\text { PVF5 - } \\
\text { Operacionalização: } \\
\text { administrativo }\end{array}$} & \begin{tabular}{|l|l|} 
PVE14 \\
\end{tabular} & Adm. Comunicação Docente & -100 & of & 100 & 200 & $86 \%$ \\
\hline & PVE15 & Adm. Comunicação Discente & -100 & 0 & 100 & 200 & $14 \%$ \\
\hline \multirow{3}{*}{$\begin{array}{l}\text { PVF6 - } \\
\text { Operacionalização: } \\
\text { pedagógico }\end{array}$} & |PVE16 & Ped. Cursos & -100 & 0 & 100 & 180 & $60 \%$ \\
\hline & \begin{tabular}{|l|} 
PVE17 \\
\end{tabular} & Ped. Comunicação Docente & -100 & 0 & 100 & 200 & $33 \%$ \\
\hline & PVE18 & Ped. Comunicação Discente & -100 & 0 & 100 & 200 & $7 \%$ \\
\hline
\end{tabular}

Fonte: Elaborado pelos autores

Após a elaboração das etapas anteriores, aplicou-se o modelo proposto, em um curso de Especialização na área de gestão da Unisul, escolhido aleatoriamente, para que fosse possível testar a viabilidade do uso de tal sistema de avaliação. No quadro 3 estão identificadas partes das respostas. Estas respostas foram dadas pelo coordenador do curso, a partir do nível que eles julgavam ser mais importante na escala. 


\section{Quadro 3: Questionário aplicado ao coordenador do curso}

MARCA
\begin{tabular}{|l|l|||}
\hline \multicolumn{1}{|c|}{ Descritor: Credenciamento } \\
\hline Niveis & Rescrição \\
\hline N2 & Rossui credenciamento com associações da área. \\
\hline N1 & Não possui credenciamento com associações da área. \\
\hline \hline
\end{tabular}

\begin{tabular}{|l|l|||}
\hline \hline \multicolumn{2}{|c|}{ Descritor: Certificação } \\
\hline Niveis & Rescrição \\
\hline N2 & Possui certificação do conselho da área. \\
\hline N1 & Não possui certificação do conselho da área. \\
\hline \hline
\end{tabular}

\begin{tabular}{|l|l|||}
\hline \hline \multicolumn{2}{|c|}{ Descritor: Tradição } \\
\hline Niveis & Rescrição \\
\hline N4 & Atuante no mercado acima de 50 anos \\
\hline N3 & Atuante no mercado de 30 a 49 anos \\
\hline N2 & Atuante no mercado de 10 a 29 anos \\
\hline N1 & Atuante no mercado de 0 a 9 \\
\hline
\end{tabular}

Fonte: Elaborado pelos autores

Com o questionário respondido pelo coordenador elaborou-se o Gráfico 1.

Gráfico 1: Curso Gestão

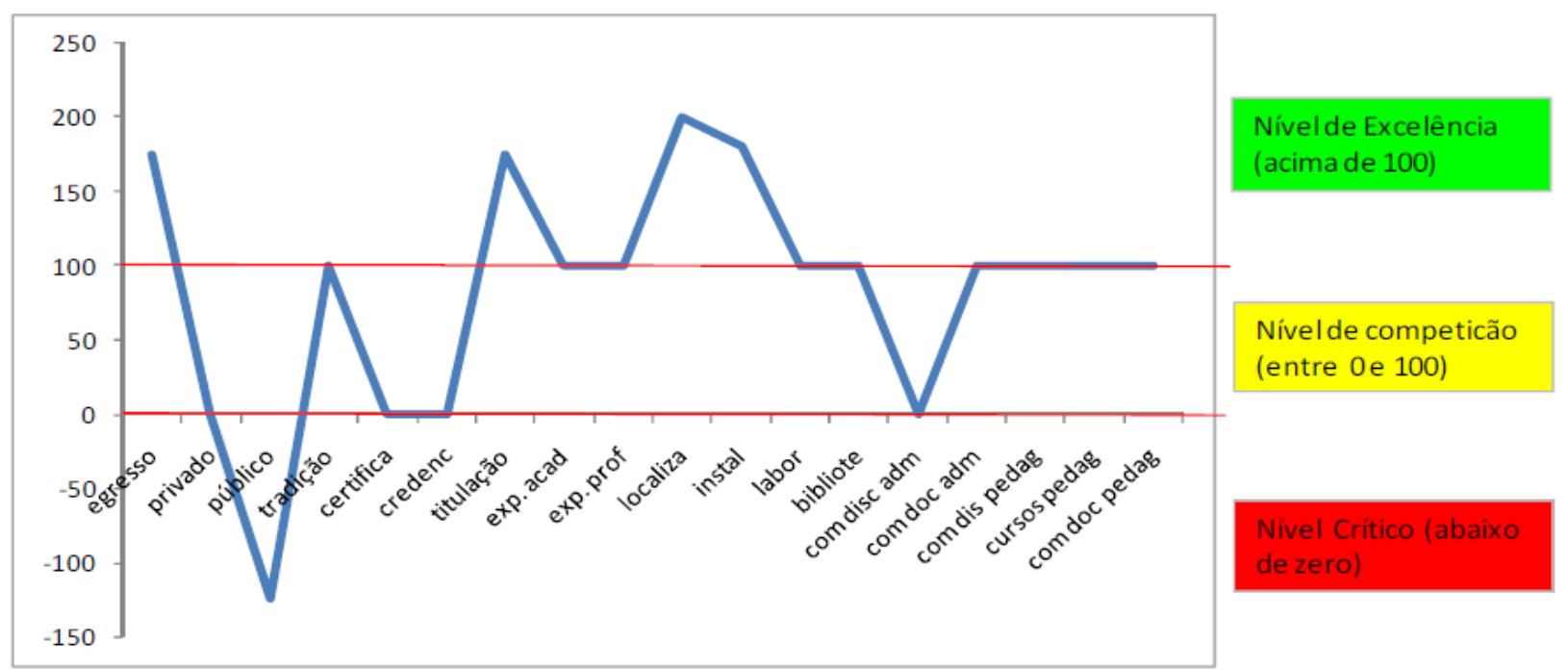

Fonte: Elaborado pelos autores

De acordo com os resultados apresentados no gráfico, puderam-se perceber onde cada um dos descritores encontra-se nivelado, quais estão na "zona de conforto" e quais precisam de atenção especial.

\section{FASE DE RECOMENDAÇÕES}

Analisando o gráfico do curso podem-se identificar quais os pontos devem ter ações corretivas e quais os pontos positivos que merecem atenção para a manutenção ou aumento de pontuação. Grande parte dos casos a oferta está em nível de competição, considerado de "mercado". Caso a universidade trabalhe com preços superiores ao mercado, é aconselhável que tenha descritores em nível de excelência.

Considerando os valores encontrados no Gráfico 1, identifica-se que as parcerias com entidades 
públicas apresenta nível crítico. Assim, este descritor necessita um conjunto de ação para elevá-lo a um nível aceitável. Já a titulação dos professores, a localização e instalações físicas foram consideradas como níveis de excelência, ou seja, são os descritores que podem ser considerados diferenciais do curso.

Assim, como o objetivo da Universidade é oferecer cursos de qualidade, é aconselhável que a maioria dos descritores seja considerada superiores ao nível de competição. Isto porque, os itens que estão classificados como nível crítico são considerados pior do que os concorrentes, já no nível de competição estão na média do mercado.

\section{CONSIDERAÇÕES FINAIS}

Como já foi dito anteriormente, o objetivo do deste artigo é apresentar uma estrutura de avaliação de desempenho para um curso de pós-graduação lato sensu na área de gestão, utilizando a metodologia MCDA-C. Para apresentação da proposta foi utilizado o caso de um cursos de Pós-graduação lato sensu de uma instituição comunitária de ensino superior, a Unisul.

Pode-se observar que o MCDA é uma metodologia que leva em consideração tanto os aspectos qualitativos quanto os quantitativos do problema. Portando entende-se que tal metodologia pode ser considerada apta para avaliar o desempenho do curso de um pós-graduação lato sensu da Unisul. Se este modelo for aplicado aos demais cursos lato sensu da instituição, o gestor de pós graduação terá condições de medir e avaliar o desempenho de cada um dos cursos e tomar as providencias cabíveis, quando necessária.

Como resultados da pesquisa destacam-se que todos o curso tem como nível crítico a parceria com o mercado. Já a titulação do professores e a localização dos cursos foram consideradas nível de excelência. No grupo classificado como mercado, o curso teve os piores resultados. 0 curso teve nível crítico em um dos três descritores. Já os grupos Marca e Operacionalização tiveram para todos os descritores nível de competição. Os descritores Docente e Infra-Estrutura tiveram alguns itens classificados como nível de excelência, mas a maioria como nível de competição.

Assim, com a implantação do MCDA existe a possibilidade de identificação e visualização do desempenho dos cursos, desde espaço físico até a qualificação do professor. Permite identificar os pontos onde a intervenção de melhorias é mais urgente, quando os resultados correspondem aos itens abaixo de "neutro" bem como a manutenção de bons níveis quando este está em "excelência".

Portanto a metodologia MCDA cumpre com a tarefa apoio ao gerenciamento de cursos de pós graduação, pois é capaz de extrair elementos relevantes ao bom desempenho dos cursos além de possibilitar uma visão global do sistema.

Com este artigo os autores esperam ter contribuído com a expansão, no contexto gerencial, da metodologia MCDA como modelo de avaliação aplicado em cursos de pós-graduação lato sensu. Para pesquisas futuras sugere-se: a implantação e análise em outros cursos de universidade estudada, além de cursos de pós-graduação lato sensu de outras instituições de ensino superior.

\section{REFERÊNCIAS}

BURGER ; HERMANN, I. L. ; BITENCOURT, L.G. ; GUERRA, J. B. S. O. A. ; BENETTI, G.M.F ; MAZON, G. . Perspectivas para a Pós-Gradução Latu-Sensu. 2008.

CAMPOS, M. L. de. Um processo de estruturação do conhecimento organizacional. Tese, Programa de Pós-Graduação em Engenharia de Produção, Universidade Federal de Santa Catarina, Florianópolis, Brasil, 2005.

COLOSSI, N.; CONSENTINO, A.; QUEIROZ, E. G. de. Mudanças no contexto do ensino superior no Brasil: uma tendência ao ensino colaborativo. Revista FAE Business School. v. 4. n.1, p.49-58, jan./ abr. 
2001.

DYER, J. S., SARIN, R. K. Measurable Multiattribute Value Functions. Operations Research, v. 27, n. 4, July - August, 1979.

DUTRA, A. ; Ensslin, L. ; Ensslin, S.R. . Elaboração de um Sistema de Avaliação de Desempenho dos Recursos Humanos da Secretaria de Estado da Administração do Estado de Santa Catarina à Luz da Metodologia Multicritérios em Apoio à Decisão. In: 9o CONGRESSO NACIONAL DE INVESTIGAÇÃO OPERACIONAL, 1998, Lisboa.

Procedimentos do 9o Congresso Nacional de Investigação Operacional, 1998. v. V1.

ENSSLIN, L.; MONTIBELLER NETO, G.; NORONHA, S. M.D. Apoio à Decisão: Metodologia para Estruturação de Problemas e Avaliação Multicritérios de Alternativas. Florianópolis: Insular, 2001.

ENSSLIN, S. R. A Incorporação da Perspectiva Sistêmico-Sinergética na Metodologia MCDAConstrutivista: Uma Ilustração de Implementação. Tese, Programa de Pós-Graduação em Engenharia de Produção, Universidade Federal de Santa Catarina, Florianópolis, Brasil, 2002.

ENSSLIN, L. Multicritério de Apoio à Decisão - MCDA I. Notas de Aula, Programa de Pós-Graduação em Engenharia de Produção, Universidade Federal de Santa Catarina, Florianópolis, Brasil, 2003.

GIL, A. C. Como elaborar projetos de pesquisa. São Paulo: Atlas, 2002.

GOODWIN, P., WRIGHT, G. Decision Analysis for Management Judgement. Chichester: John Wiley \& Sons, 1991.

GOERGEN, P. A avaliação universitária na perspectiva da pós-modernidade. Revista da rede de avaliação institucional da educação superior. Campinas. v. 2, n. 3, p. 53-66, 1997.

HAMILTON, D. Muito além de um sonho: a história da Unisul. Tubarão: Editora Unisul, 2001.

INEP. Instituto Anísio Teixeira. INEP, ano 5, n. 145, 2007. Disponível em: http://www.inep.gov.br/informativo/informativo145.htm. Acesso em 04 dez. 2008.

KEENEY, R. L. Value Focused-Thinking: A Path to Creative Decision-making. Cabridge: Harvard Univ.Press, 1992.

LANDRY, M. A Note on the Concept of "Problem". Organization Studies, 1995.

LDB. Lei de Diretrizes e Bases para a Educação (Lei no 9.394 de 20 de dezembro de 1996)

ROY, B. Decision science or decision-aid science? European Journal of Operacional Research, v.8, n.1, pp. 184-203,1993.

SILVEIRA, G. L. J. da; HERDT, S. S. Carta-Compromisso: Unisul - o presente e o futuro das próximas gerações. In: MARKUN, Paulo;

SOBRINHO, J. D.; RISTOFF, D. I. (orgs.). Universidade desconstruída: avaliação institucional e resistência. Florianópolis: Insular, 2000, p. 34.

TEIXEIRA, A. S. Ensino Superior no Brasil: análise e interpretação de sua evolução até 1969. Rio de Janeiro: Editora UFRJ, 2005.

VAHL, T. R., Alternativas de financiamento para o ensino superior. Florianópolis: NUPEAU, 1992.

VERGARA, S. C. Métodos de pesquisa em administração. São Paulo: Atlas, 2005.

YIN, R. K. Estudo de caso: Planejamento e Métodos. Porto Alegre. Bookman, 2005. 